\title{
EXPERIÊNCIA PEDAGÓGICA DE PROFESSORES KARAYWA'NA ALDEIA INDÍGENA MAPUERA, ORIXIMINÁ-PA
}

\author{
Ana Cely de Sousa Coelho2 \\ Messias Furtado da Silva ${ }^{3}$
}

\section{RESUMO}

Educação escolar indígena consubstanciada em diálogo intercultural que respeite o jeito de ser e viver de cada povo, apesar de garantida nos marcos legais, ainda é uma realidade a ser construído por muitas maõs. Neste artigo, apresentamos resultado de pesquisa sobre a experiência pedagógica de professores nãoindígenas na educação escolar do povo indígena Wai-Wai da aldeia Mapuera, município de Oriximiná/PA, com o objetivo de analisar as relações, diálogos e dificuldades enfrentadas por estes na efetivação da educação intercultural em aldeia indígena. A constituição dos dados ocorreu por meio de entrevista semiestruturada com professores que atuam no ensino fundamental da Escola Indígena Mapuera. Os resultados mostram desafios, entraves, dificuldades e potencialidades em efetivar a educação intercultural, instrumento de luta dos povos indígenas pela preservação da cultura e tradições indígenas.

Palavras-chave: Educação Escolar Indígena. Interculturalidade. Prática Pedagógica.

\section{EDUCATIONAL EXPERIENCE OF KARAIWA TEACHERS IN MAPUERA INDIGENOUS VILLAGE, ORIXIMINA-PA}

\begin{abstract}
Indigenous school education founded on intercultural dialogue that respect the way of being and living of each people, although guaranteed in law, is still a reality to be

\footnotetext{
1 Não índio, na língua wai-wai. Outros povos se referem ao não índio de forma diferente. Napẽ para os Yanomami, Kupẽ para os Gavião, kubẽ para os Mẽbẽngôkre, Kamara para os Surui Aikewara, Toria para os Parakana, kaminja para os Waimiri Atroari, Karaiw para os Tembé, entre outros.

2 Mestra em Recursos Aquáticos Continentais Amazônicos - Universidade Federal do Oeste do Pará - UFOPA (2015). Docente na Universidade do Estado do Pará - UEPA/Campus XII no Curso de Licenciatura Intercultural Indígena - pelo Plano de Formação de Professores PARFOR/UEPA. E-mail: anacely_vepa@hotmail.com

3 Doutorando do Programa de Pós-Graduação em Educação Para a Ciência (UNESP/BauruNível 6 CAPES): Professor do Curso de Licenciatura Intercultural Indigena; Professor Formador do Programa Ação Saberes Indígenas na Escola (MEC/SECADI). E-mail: furtadodasilva2009@hotmail.com
} 
built by many hands. This article presents results of research about the pedagogical experience of non-indigenous teachers in the education of the indigenous people Wai-Wai of Mapuera village, municipality of Oriximiná/PA, in order to analyze the relations, dialogues and difficulties faced by teachers in the effectiveness of a proposal for intercultural education in Indigenous villages. Data were possible through literature review and semi structured interview with teachers who work in primary education of the indigenous school Mapuera. The results show that there is still a long way to go to an indigenous education that is instrument of struggle for the preservation of indigenous culture and traditions.

Keywords: Indigenous school education. Interculturality. Educational practice.

\section{EXPERIENCIA PEDAGÓGICA DE PROFESORES KARAYWA EN ALDEIA INDÍGENA MAPUERA, ORIXIMINÁ-PA}

\section{RESUMEN}

La construcción de una educación escolar indígena basada en el diálogo intercultural y en el respeto a la forma de ser y vivir de cada pueblo indígena, aunque garantizada en los marcos legales, sigue siendo un sueño a ser construido por muchas voces. En este artículo presentamos resultados de investigación que cuenta la experiencia pedagógica de profesores no indígenas en la educación escolar del pueblo indígena Wai-Wai de la aldea Mapuera, municipio de Oriximiná / PA, con el objetivo de analizar las relaciones, diálogos y dificultades enfrentadas por profesores En la efectividad de una propuesta de educación intercultural en aldea indígena. Los datos fueron posibles por medio de la búsqueda de la literatura y las respuestas a la entrevista semiestructurada con profesores que actúan en la enseñanza fundamental de la Escuela Indígena Mapuera. Los resultados muestran gran desafios, a través de dificultades y potencialidades, para efectivizar la educación intercultural, instrumento de lucha de los pueblos indígenas por la preservación de la cultura y tradiciones indígenas.

Palabras clave: Educación Escolar Indígena. Interculturalidad. Práctica pedagógica.

\section{INTRODUÇÃO}

A educação indígena em toda a história brasileira sempre foi profundamente marcada pela tentativa de conversão dos índios a chamada sociedade nacional, impondo-lhes a força o modo de vida, crenças e costumes do colonizador. Segundo Secchi (2002) O modelo integracionista de educação escolar para o índio no Brasil está associado historicamente ao binômio proselitismo doutrinário (religioso ou não) e preparação para o trabalho. Com esse intuito, atuaram as missões católicas, 
as escolas pombalinas, a educação positivista e, mais recentemente, os missionários e linguistas de diferentes confissões. Alvares (1999) lembra que além da invasão de suas terras tradicionais e a destruição de suas riquezas naturais e populações, as sociedades indígenas foram "brindadas" pelos agentes coloniais com atividades escolares de caráter civilizatório e missionário.

Esta forma heterônoma de fazer educação foi quebrada, ao menos no plano legal, pelo advento da Constituição da República Federativa do Brasil de 1988 (CRFB/88), que no título da ordem social (título VIII), declara ser reconhecidos aos índios sua organização social, costumes, línguas, crenças e tradições, e os direitos originários sobre as terras que tradicionalmente ocupam. Este reconhecimento é um marco na luta dos povos indígenas por uma educação diferenciada, desencadeando as legislações posteriores que desenharam a educação escolar indígena intercultural e bilíngue (EIB), afinada aos preceitos culturais identitários de cada povo.

Entre as leis infraconstitucionais, merece destaque a lei 9394/96, de diretrizes e bases da educação nacional (LDBEN), que no artigo 78, estatui que o Sistema de Ensino da União, com a colaboração das agências federais de fomento à cultura e de assistência aos índios, desenvolverá programas integrados de ensino e pesquisa, para oferta de educação escolar bilíngue e intercultural aos povos indígenas, proporcionando aos índios, suas comunidades e povos, a recuperação de suas memórias históricas; a reafirmação de suas identidades étnicas; a valorização de suas línguas e ciências, bem como garantir aos índios, suas comunidades e povos, o acesso às informações, conhecimentos técnicos e científicos da sociedade nacional e demais sociedades indígenas e não índias.

A LDBEN desencadeia a regulação do funcionamento da educação escolar indígena. Em 1998, o ministério da educação, por meio da Secretaria de Ensino Fundamental (SEF), dá um passo significativo nesse sentido, publicando os referenciais curriculares nacionais para as escolas indígenas (RCNEI/1998), com base nos princípios que lhe são próprios e ainda: 


\section{ISSN 2237-9460}

- Uma visão de sociedade que transcende as relações entre humanos e admite diversos "seres" e forças da natureza com os quais estabelecem relações de cooperação e intercâmbio a fim de adquirir - e assegurar - determinadas qualidades;

- Valores e procedimentos próprios de sociedades originalmente orais, menos marcadas por profundas desigualdades internas, mais articuladas pela obrigação da reciprocidade entre os grupos que as integram;

- Noções próprias, culturalmente formuladas (portanto variáveis de uma sociedade indígena a outra) da pessoa humana e dos seus atributos, capacidades e qualidades;

- Formação de crianças e jovens como processo integrado; apesar de suas inúmeras particularidades, uma característica comum às sociedades indígenas é que cada experiência cognitiva e afetiva carrega múltiplos significados - econômicos, sociais, técnicos, rituais, cosmológicos.

O RCNEl é o ponto de partida para a implantação de diversas escolas com características bilíngues, depois dele, o decreto 6.861, de 27 de maio de 2009, o governo federal regulamentou a educação escolar indígena, estatuindo que esta seria organizada com a participação dos povos indígenas, observada a sua territorialidade e respeitando suas necessidades e especificidades, com base nos seguintes objetivos:

- Valorização das culturas dos povos indígenas e a afirmação e manutenção de sua diversidade étnica;

- Fortalecimento das práticas socioculturais e da língua materna de cada comunidade indígena;

- Formulação e manutenção de programas de formação de pessoal especializado, destinados à educação escolar nas comunidades indígenas;

- Desenvolvimento de currículos e programas específicos, neles incluindo os conteúdos culturais correspondentes às respectivas comunidades; 
- Elaboração e publicação sistemática de material didático específico e diferenciado;

- Afirmação das identidades étnicas e consideração dos projetos societários definidos de forma autônoma por cada povo indígena.

O decreto também reconhece às escolas indígenas a condição de escolas com normas próprias e diretrizes curriculares específicas, voltadas ao ensino intercultural e bilíngue ou multilíngue, gozando de prerrogativas especiais para organização das atividades escolares, respeitado o fluxo das atividades econômicas, sociais, culturais e religiosas e as especificidades de cada comunidade, independentemente do ano civil.

Com o decreto 6.861/2009 estão consolidadas as bases legais para a criação nas aldeias de ElB, fundada no respeito a cultura, as tradições, ao modo de ser e viver de cada povo. Mas a legislação é um dever-ser, espécie de carta de intenção da sociedade. Sua concretização depende do trabalho e do compromisso de um corpo de indivíduos que se dispõe ao desafio de arrostar com o desconhecido, de conviver com o diferente e é neste ponto que situamos este estudo, nele pesquisamos sobre a experiência de professores karaywa que atuam no ensino fundamental da Escola Indígena Wai-Wai, localizada na aldeia Mapuera, município de Oriximiná, região oeste do Estado do Pará/Brasil.

Nosso objetivo foi compreender como se dá a experiência de professores não índios na escola da aldeia, quais suas perspectivas e dificuldades; como se organiza o ensino, quais os desafios enfrentados e como são as relações entre os professores karaywa, os professores Wai-Wai, os professores do ensino médio e os demais membros da comunidade.

Para responder a estes questionamentos mergulhamos no universo da aldeia Mapuera e, neste artigo, apresentamos o resultado da pesquisa, na certeza de que estamos contribuindo para que a educação seja um instrumento de afirmação da cultura e de identidade dos povos e que a experiência docente vivenciada no cotidiano na Aldeia Mapuera seja contributo para a assunção de práticas docentes interculturais na diferenciada educação indígena. 


\section{MATERIAIS E MÉTODO}

\subsection{Conhecendo o local da pesquisa}

A Aldeia Mapuera está situada às margens do rio Mapuera, município de Oriximiná-PA e pertence a um complexo formado por 18 aldeias (Mapuera, Bateria, Pomkuru, Tamyuru, Placas, Paraíso, Inajá, Takará, Kwanamari, Mapium, Passará, Yawará, Tawaná, Santidade, Chapéu, Kaspakuru, Turuni, Ayaramã), onde vivem aproximadamente 2086 indígenas oriundos das etnias Wai-Wai, Hiskaryana, Tunayana, Katuena, tiriyó, Xereu, Manawana e Kaxuyana. Mapuera é a maior destas aldeias, onde vivem aproximadamente 1300 indígenas predominantemente da etnia Wai-wai. (Fonte: Liderança Indígena). O povo wai-wai é falante da língua do mesmo nome, variante do tronco caribe. O termo Wai-wai significa mandioca, referindo-se à tonalidade da pele dos indígenas.

É uma sociedade em que a mulher se destaca nas atividades laborais seja doméstica como o preparo alimentar e o cuidado com os filhos, seja na lida rural - desde o transporte, ao preparo da terra e o plantio. Elas praticam atividades que exigem bastante força física como o carregamento de lenha, mandioca e macaxeira no xamanxim (tipo de cesto que carrega nas costas com capacidade de 70 a $90 \mathrm{~kg}$ ), preparação da terra com a destocagem, roça e plantio, além das atividades domésticas como o transporte de água. Isto em função do homem indígena Wai-Wai ser o responsável pela proteção feminina (precisa estar com as mãos livres e ágeis para proteger sua família, caso ocorra um ataque de animais silvestres, por exemplo) e provedor do sustento com a atividade da caça e pesca.

Os indígenas Wai-Wai desenvolvem atividades produtivas de diversos itens alimentares (banana, abacaxi, milho, mandioca, macaxeira, dentre outros) existem aqueles que são retirados diretamente da natureza como o açaí, a bacaba e o buriti a qual misturados com a tapioca formam a gororoba (vinho grosso de tapioca), também praticam a caça de animais silvestres e a pesca, estes funcionam como a base alimentar do indígena de Mapuera, que faz diversas refeições ao dia. 
Há uma religiosidade protestante - Batista - presente na aldeia, onde aos domingos ocorrem cultos de louvor, onde há reunião na casa grande "umanama" para cantorias e rezas. Participam crianças, jovens e adultos das orações ao som do chamado matutino do pastor via rádio suspenso volante fixo em poste central na aldeia.

A educação básica é dividida em ensino fundamental e médio. No ensino fundamental, do $1^{\circ}$ ao $5^{\circ}$ ano os professores são exclusivamente indígenas e as aulas são ministradas na língua Wai-Wai. Do $6^{\circ}$ ao $9^{\circ}$, as aulas são ministradas em língua portuguesa, por professores indígenas e não indígenas. O ensino médio é ofertado pelo sistema modular de ensino (SOME), com predominância de professores não indígenas. A Escola Indígena Wai-Wai tem aproximadamente 800 alunos matriculados, 580 no ensino fundamental e 220 no ensino médio.

\subsection{Conhecendo os participantes da pesquisa}

Quadro 1: Participantes da pesquisa

\begin{tabular}{|l|l|l|l|l|l|l|}
\cline { 3 - 7 } \multicolumn{1}{l|}{} & Idade & Origem & Formação & $\begin{array}{l}\text { Ano de } \\
\text { conclusão } \\
\text { do ensino } \\
\text { superior }\end{array}$ & $\begin{array}{l}\text { Ano de } \\
\text { ingresso } \\
\text { na } \\
\text { aldeia }\end{array}$ & $\begin{array}{l}\text { Tempo médio } \\
\text { mensal de } \\
\text { permanência } \\
\text { na aldeia }\end{array}$ \\
\hline $\begin{array}{l}\text { Participante } \\
1\end{array}$ & 29 Anos & $\begin{array}{l}\text { Oriximiná- } \\
\text { PA }\end{array}$ & $\begin{array}{l}\text { Pedagogi } \\
\text { a }\end{array}$ & $\begin{array}{l}\text { Em } \\
\text { andamento }\end{array}$ & 2012 & 26 dias \\
\hline $\begin{array}{l}\text { Participante } \\
\text { Participante } \\
3\end{array}$ & 28 Anos & $\begin{array}{l}\text { Porto } \\
\text { Velho - RO }\end{array}$ & $\begin{array}{l}\text { História e } \\
\text { Geografia }\end{array}$ & 2010 & 2009 & 30 dias \\
\hline
\end{tabular}

Fonte: Participantes

Os participantes são falantes da língua portuguesa e conhecem algumas palavras em Wai-wai - geralmente as mais utilizadas na escola aprendidas na convivência com os alunos, professores indígenas e pessoas da comunidade. 


\subsection{Buscando um método apropriado}

A proposta da pesquisa bem se encaixa na definição de Deslandes (2007), como um exercício científico artesanal e intelectual. Nossa ida a aldeia Mapuera deu-se em razão do trabalho no Curso de Licenciatura Intercultural Indígena da Universidade do Estado do Pará (UEPA), curso de formação de professores indígenas com os índios Wai-Wai da aldeia Mapuera e, para isto fomos abrigados pela liderança indígena ${ }^{4}$ na Casa dos Professores 5 do ensino fundamental da aldeia, passando a conviver com os mesmos e acompanhando as atividades de planejamento pedagógico e as tarefas cotidianas que se realizavam na casa e na escola.

Nesse processo de convivência, ao mesmo tempo que íamos ganhando a confiança dos professores, fomos amadurecendo a ideia de contar a comunidade acadêmico-científica a experiência que estávamos vivenciando. Nesse movimento aproximativo, fomos criando condições para constituição dos dados, levando em consideração o alerta de Pêcheux (2014), de que um discurso é sempre pronunciado a partir de condições de produção dados.

Para dar conta de uma pesquisa de características singulares como a que nos propomos desenvolver, passamos a entender metodologia a partir da intuição de Minayo (2007) como o caminho do pensamento e a prática exercida na abordagem da realidade, incluindo simultaneamente a teoria da abordagem, os instrumentos de operacionalização do conhecimento e a criatividade do pesquisador.

Desenvolvemos um roteiro de entrevista semiestruturada, com questões geradoras que cobrissem todo o desejado para descrever a experiência dos professores que atuam na escola da aldeia:

\footnotetext{
${ }^{4}$ Todos os visitantes da aldeia devem obter permissão para ingressar e permanecer na mesma, seguindo as regras de convivência estabelecidas pelo grupo social.

${ }^{5} \mathrm{Na}$ aldeia existe outra casa, para os professores do ensino médio. As duas casas foram construídas para abrigar os professores Karaywa que ensinam na escola da aldeia.
} 
1 - Conte-nos sobre sua experiência como professora Karaywa na Aldeia Indígena Mapuera (chegada, dificuldades, perspectivas, família, distância, aprendizagem, linguagem...).

2- Os alunos indígenas da Aldeia Mapuera são alfabetizados e estudam do $1^{\circ}$ ao $5^{\circ}$ ano na Língua Caribe. Dentro dessa realidade, quais os desafios que você enfrenta para ensinar na Aldeia Mapuera?

3- Quais as relações existentes entre você, professor Karaywa, com os demais professores indígenas e os demais educadores da Aldeia Mapuera? E com a comunidade indígena local?

A opção pela entrevista semiestruturada segue a lógica expressa por Trivinõs (2011), de deixar o informante seguir espontaneamente a linha de seu pensamento e de suas experiências dentro do foco principal colocado pelo investigador e este começa a participar da investigação. Os próprios participantes sugeriram que formulássemos as questões e entregassem a eles, pois assim teriam a possibilidade de responder com mais calma, sem interrupções, por não termos na aldeia um local onde a entrevista fosse realizada sem interrupções.

A pesquisa foi realizada no período de 06 a 14 de novembro de 2015, na aldeia Mapuera, Terra Indígena Wai-Wai, município de Oriximiná/PA.

Organizamos os dados em duas categorias amplas: Língua, organização do ensino e prática docente; e interculturalidade e convivência na aldeia. Organizamos os dados em categorias adotando o magistério de Bardin (2002), que infere ser esta, no conjunto das técnicas da análise de conteúdo, cronologicamente a mais antiga e na prática a mais utilizada, por funcionar por operações de desmembramento do texto em unidades, em categorias segundo reagrupamentos analógicos.

Dentre as técnicas de análise de conteúdo oferecidas por Bardin (op. cit), elegemos para análise dos dados a análise de asserção avaliativab, elaborada por Osgood, Saporta e Nunnally. Esta técnica tem por finalidade medir as atitudes do locutor quanto aos objetos de que ele fala. O objetivo

${ }^{6}$ Evaluative Assertion Analysis (E. A. A.) 
da aplicação desta técnica é encontrar as bases das atitudes dos interlocutores, no caso os professores Karaywa por trás da dispersão das manifestações verbais.

\begin{abstract}
A concepção da linguagem em que esta análise se fundamenta é chamada representacional, isto é, considera-se que a linguagem representa e reflete diretamente aquele que a utiliza. Por conseguinte, podemos nos contentar com os indicadores manifestos, explicitamente contidos na comunicação para fazer inferências a respeito da fonte de emissão. A análise de asserção avaliativa de Osgood tira partido dos conhecimentos da psicologia social sobre a noção de atitude. Uma atitude é uma pré-disposição, relativamente estável e organizada, para reagir sob forma de opiniões (nível verbal), ou de atos (nível comportamental), em presença de objetos (pessoas, ideias, acontecimentos, coisas, etc.) de maneira determinada (BARDIN, 2002, p. 155/156).
\end{abstract}

\title{
3 RESULTADOS E DISCUSSÃO
}

A experiência aqui contada parte do olhar do professor Karaywa sobre sua relação com a educação escolar indígena na aldeia Mapuera, permeada por significados que devem ser interpretados levando em consideração as condições de produção da pesquisa e de atuação dos participantes na escola da aldeia.

Outras experiências neste sentido já foram relatadas, destacamos estudos de Cohn (2001), sobre a experiência de professores indígenas na educação escolar indígena no Estado do Maranhão, que buscou desvelar as representações que fazem os indígenas sobre o significado do trabalho que realizam; de Perrelli (2007), que conta sua experiência como professora de ciências entre alunos indígenas Kaiowa e Guarani do Mato Grosso do Sul; e de Bergamaschi (2005), sobre a experiência de implantação das escolas indígenas nas aldeias Guarani do Rio Grande do Sul e a controvérsia que se instalou quando parte deste povo prescindiu da escola por avaliar que a educação tradicional, desenvolvida naturalmente, era suficiente para viver na aldeia.

Em razão das questões geradoras cobrirem um largo espectro, preferimos dividir o conteúdo das falas em categorias temáticas, assim entendidas por Pêcheux (2014) como uma série de significações que o 
codificador detecta por meio dos indicadores que the estão ligados. Os indicadores nos levaram a distribuir o conteúdo nas seguintes categorias:

\title{
3.1 língua, organização do ensino e prática docente.
}

\begin{abstract}
"Minha turma tem 28 alunos, em que 18 conseguem entender 0 português e fazem as atividades, os demais não, tenho que explicar para eles quando não conseguem com o que falo, coloco exemplo no quadro para poderem entender, mesmo assim fico perdida na sala de aula porque eu não sei se eles estão entendendo porque nós não temos um professor indígena para acompanhar, para explicar o que estamos passando de conteúdo, trabalho e atividades" (participante 1).
\end{abstract}

Villares (2013), defende que respeitar os direitos dos povos indígenas passa pelo reconhecimento do Brasil como estado pluriétnico e multicultural, que convive com diversas culturas e formas de organização social. Dentro dessas características, os direitos são poliétnicos, garantem a expressão e o orgulho da diferença e procuram preservar e proteger a riqueza e diversidade cultural. São direitos que trazem a proteção contra o racismo, o preconceito e a discriminação e a imposição pela sociedade e pelo Estado da cultura majoritária e que promovem as manifestações culturais, como as línguas, religiões, costumes, crenças etc.

$\mathrm{Na}$ concepção de estado pluriétnico, temos no Brasil, segundo Luciano (2006) cerca de 220 povos indígenas falantes de 180 línguas, com cerca de 734 mil indivíduos. Especificamente na aldeia Mapuera, os indígenas são falantes da língua wai-wai, do tronco Caribe, daí a primeira barreira de comunicação encontrada pelos professores karaywa.

As diretrizes curriculares para a educação escolar indígena na educação básica reconhecem na educação indígena a importância das línguas indígenas e dos registros linguísticos específicos do português para o ensino ministrado nas línguas maternas das comunidades indígenas, como uma das formas de preservação da realidade sociolinguística de cada 
povo. Freire (2014) nos lembra que uma língua contém nela todo o território em que é falada na medida em que classifica, nomeia, descreve, avalia, hierarquiza e dá sentido a tudo que nela existe.

Flora, fauna, acidentes geográficos, seres encantados e desencantados que o povoam, além de crenças e conhecimentos que revelam a relação entre eles. As línguas não só "comunicam" informações [...], mas realizam toda uma série de práticas sociais, construindo discursos que estabelecem vínculos sociais, ritualizam, contam histórias, cantam, brigam, amam e contribuem para criar comunidades que se formam justamente com essas afinidades (FREIRE, 2014, p. 363).

Como membro de outro campo7, integrante de outra cultura, o karaywa, apesar do tempo de convivência e do esforço empreendido para comunicar-se, não domina a língua wai-wai por não pertencer ao grupo, é um estrangeiro 8 vindo à aldeia para comunicar a ciência e cultura do não índio, necessária, mais não imprescindível.
"Vivemos aqui na aldeia, até hoje trabalhando com a turma $6^{\circ}$ ano em 2012, 2013 e 2014 atuando no programa mais educação, em 2015 na coordenação deste e com o $5^{\circ}$ ano. Essa turma de $5^{\circ}$ ano que recebi no ano passado (2014) é novamente um ensaio, não é definitivo saber como será para avaliar como eles vão para o $6^{\circ}$ ano, porque eu não sei falar uma frase em wai-wai, então sei algumas palavras que dá de entender mas conversar com eles em wai-wai, que dá para entender eu não sei" (participante 1). demais, alunos principalmente quando fui lotado para ministrar $\circ 5^{\circ}$ ano" (participante 3). "Aprendi a falar um pouco Wai-Wai, através da convivência com os

Convém esclarecer que a adoção do ensino na língua materna é também movimento de resistência, o RCNEl (1998) descreve que para que a língua portuguesa se tornasse a língua de maior poder linguístico e, por isso,

\footnotetext{
7 Aqui nos valemos do conceito de campo de Bourdieu (1989), campo como local onde acontecem as coisas, onde se desenvolve a cultura.

8 O termo é aqui usado para designar os indivíduos externos ao grupo, que participam do grupo por algum tempo e observam o grupo com olhar externo a este. Utilizamos este viés de etno sob a ótica de Erickson (1986) que identificou na origem da palavra etnografia a designação dada aos povos considerados estrangeiros, possuidores de uma cultura externa a da civilização grega.
} 
a língua oficial do país, foi preciso que ela lutasse contra as línguas indígenas, numa guerra linguística que continua até hoje. Quando os primeiros portugueses chegaram ao Brasil havia aqui aproximadamente 1300 línguas indígenas, hoje há aproximadamente 180 línguas, mesmo assim, muitos povos usam sua língua nativa como segunda língua.

Quando se considera a sobrevivência das línguas indígenas, tem-se que pensar também em outras armas usadas contra elas e que foram e são tão perigosas quanto o genocídio. Uma das maneiras utilizadas por falantes de línguas dominantes para manter o seu poder linguístico é demonstrar desprezo pelas línguas minoritárias: é referir-se a elas como "gírias", "dialetos", línguas pobres" ou "línguas imperfeitas". Isso faz com que os falantes indígenas passem a se envergonhar de suas línguas, passem a ter atitudes negativas em relação a elas, terminando por abandoná-las (RCNEl, 1998, p. 117).

Uma das mais significativas lutas dos povos indígenas da atualidade é pelo reavivamento de suas línguas, consideradas fundamentais na recuperação da memória histórica e tradições, como bem ensina Meliá (1979), uma língua tem uma história, se realimenta continuamente com novas experiências. O que se pode extrair das palavras dos participantes são arranjos para tentar se comunicar, vencer as barreiras linguísticas, no entanto, a preocupação principal está no processo formativo, pois a comunicação deficitária implica diretamente na dificuldade de transmissão de saberes e no diálogo entre culturas, fundamentais para a consolidação da escola indígena diferenciada.

A LDBEN, artigo 78, estabelece que o Sistema de Ensino da União, com a colaboração das agências federais de fomento à cultura e de assistência aos índios, desenvolverá programas integrados de ensino e pesquisa, para oferta de educação escolar bilíngue e intercultural aos povos indígenas, com o objetivo de fortalecer as práticas socioculturais e a língua materna de cada comunidade indígena. Esta garantia é ratificada nas diretrizes curriculares nacionais para a educação Indígena na educação Básica, assegurando que a educação escolar indígena deve se constituir num espaço de construção de relações interétnicas orientadas para a manutenção da pluralidade cultural, pelo reconhecimento de diferentes 
concepções pedagógicas e pela afirmação dos povos indígenas como sujeitos de direitos. A CRFB/88, no artigo 210, $\S 2^{\circ}$, estabelece que o ensino fundamental regular será ministrado em língua portuguesa, assegurada às comunidades indígenas também a utilização de suas línguas maternas e processos próprios de aprendizagem.

Na aldeia Mapuera, no entanto, a decisão de ofertar os 5 primeiros anos da educação regular exclusivamente em língua materna tem caráter relacional com o fortalecimento da língua enquanto elemento identitário do povo da aldeia, da fixação do elemento que imprime a marca de um povo, a língua, pois a criança convive na escola com a mesma língua que convive na família.

No entanto, o que parece simples sob a ótica do indígena, é complexo sob a perspectiva do karaywa, membro de outra cultura e falante de outra língua, constituindo-se em forte entrave à efetivação da proposta pedagógica da escola, como relatam os participantes:

"Não é fácil se deparar com essa situação, é uma nova língua pra gente, temos que aprender um pouquinho da deles para gente poder se comunicar com eles, porque se a gente falar uma palavrinha da língua deles Wai-Wai a gente consegue fazer com que eles entendam alguma coisa que queremos repassar em português" (participante 1).

"As dificuldades não eram poucas mais na hora de se comunicar pouco entendiam, tanto eles na língua portuguesa como nós na língua wai-wai, essa foi uma das dificuldades" (participante 2).

"A maior falta dos alunos indígenas é saber a língua portuguesa, pois somente os homens quase se comunicam com os professores "brancos", já as mulheres têm a maior dificuldade em falar o português. Mas se você se esforçar e falar a língua indígena se torna mais fácil a comunicação. Aprendi a falar um pouco Wai-Wai, através da convivência com os demais" (participante 3).

Não é demais lembrar que uma das dimensões do projeto pedagógico escolar é a constituição da identidade do sujeito, que passa pelas dimensões social, ética e política, como destaca Sousa (2010), se os 
sujeitos constituem-se no âmbito de suas relações sociais, éticas e políticas, de forma semelhante ocorre a construção do projeto político pedagógico da escola, sem perder de vista que este é um campo por excelência de produção da subjetividade dos sujeitos.

No caso em estudo, a organização é feita interpretando os dispositivos legais. Da educação infantil ao $5^{\circ}$ ano, a criança estuda exclusivamente em língua wai-wai, do $6^{\circ}$ ao $9^{\circ}$ ano em língua portuguesa e wai-wai, nesta segunda etapa do ensino fundamental, as disciplinas da base nacional comum são ministradas por professores Karaywa, e é justamente este processo de transição do aluno de uma língua para outra que cria, conforme relatos abaixo, a maior dificuldade para os professores Karaywa:

"Foi um impacto perceber que os alunos do $6^{\circ}$ ano não sabiam ler e escrever e esse trabalho seria para nós karaywa alfabetizá-los. Então, foi assim um trabalho durante um ano todo, somente de experiência de como conseguir fazer um trabalho com esses alunos indígenas" (participante 1).

$\mathrm{Na}$ escola funciona do Jardim ao $5^{\circ}$ Ano com professores indígenas (são alfabetizados na língua materna wai-wai) e do $6^{\circ}$ ao $9^{\circ}$ ano com os professores Karaywa (na língua portuguesa) e alguns professores indígenas que trabalham hora-aula. Outra realidade complicada é o desafio para nós de como fazer com que esses alunos aprendessem, é difícil, pois razoavelmente falam o português, não são todos, a maioria na verdade, eles tinham muita vergonha de se comunicar, a escrita pouco se entende, alguns da mesma forma que fala se escreve, não conseguem interpretar textos, isso conforme os textos, isso conforme os anos de $6^{\circ}$ ano é onde se encontra bastante dificuldade, até no $7^{\circ}$ ano, do $6^{\circ}$ porque é o primeiro contato com o professor não indígena, no $8^{\circ}$ ano já estão mais atentos e mais tempo com o professor karaywa, na sala de aula" (participante 2).

A utilização da língua materna nas séries iniciais, importante para o projeto societário dos Wai-wai, não é consenso na EIB em razão das diferenças nos projetos societários dos diversos povos indígenas (COHN, 2001; PERRELLI, 2007; LUCIANO, 2006; BERGAMASCHI, 2005), pois a questão não é 
simplesmente em que língua estudar, mais as tradições e significados que cada língua carrega consigo, vez que é identitária de uma cultura.

Outro conflito está nos objetivos do ensino, quando as lideranças indígenas optam pela educação escolar de preparação para as etapas superiores do ensino, que passa pela submissão ao Exame Nacional do Ensino Médio (ENEM), é mais comum que optem pelo ensino em língua portuguesa e adotem os conteúdos curriculares da Base Nacional Comum.

Muitos povos têm resistido a este tipo de escola e em alguns casos a própria escola. Luciano (2006) relata que, entre muitos questionamentos, alguns povos indígenas questionam que, numa sociedade dividida em classes, entre ricos e pobres, se a educação escolar não resolveu o problema para os não-indígenas, como resolveria para os indígenas? Outros perguntam para que serve a escola? Qual a sua utilidade? Se a escola tem por objetivo melhorar as condições de vida, de que condições de vida se está falando?

O indígena é um ser em movimento, que evolui como todas as coisas vivas e se vê enredado por múltiplas relações com o não indígena. Poucas etnias vivem isoladas, há um processo de convivência que de alguma forma influencia nas mudanças culturais dos povos indígenas, em uma espécie de hibridismo cultural. Canclini (2015) remete a dois9 movimentos básicos que constituem a modernidade, um projeto emancipador, aqui entendidos a secularização dos campos culturais e a produção auto expressiva e autorregulada das práticas simbólicas; e o projeto expansionista, que procura estender o conhecimento e a posse da natureza e a produção e circulação do consumo de bens próprios do capitalismo. O advento da educação escolar indígena pós CRFB/88, que permitem ao índio o direito de continuar índio, sustentado em uma concepção de escola intercultural e bilíngue, nos leva a considerar que o índio da aldeia Mapuera optou pelo

\footnotetext{
9 Além dos dois movimentos citados, Canclini também descreve o projeto renovador, abrangendo de um lado a busca de um aperfeiçoamento e inovação incessantes, próprios de uma relação com a natureza e com a sociedade liberada de toda prescrição sagrada de como deve ser o mundo; e o projeto democratizador, que confia na educação e na difusão da arte e dos saberes especializados para chegar a uma evolução racional e moral.
} 
movimento emancipador definido por Canclini (op. cit.), vez que a escola tem por função, nas séries iniciais, ser um dos elementos de ligação entre o indígena e sua cultura, suas tradições e jeito de ser e viver. Essa opção não é a mesma do professores Karaywa, cujo objetivo é transmitir os saberes da ciência nacional clássica, por isso as dificuldades enfrentadas, como no relato abaixo:

\begin{abstract}
"Os professores, nós e os outros, já perceberam a dificuldade, em que os professores procuram dar mais atenção aqueles alunos que já sabem alguma coisa e já conseguiam o melhor entendimento das atividades que fazem na sala de aula, eles esquecem de trabalhar aqueles alunos que tem mais dificuldade, nós percebemos que eles chegam no $6^{\circ}, 7^{\circ}, 8^{\circ}, 9^{\circ}$ ano com muita dificuldade, as vezes até de escrever da lousa, fazer seu próprio nome, tem aluno do $9^{\circ}$ ano com essas dificuldades e eles desprezam aquele aluno" (participante 1).
\end{abstract}

Os professores karaywa acreditam na educação compartilhada, que com apoio do professor indígena na utilização da língua o ensino fluiria melhor, pois nesta reside sua grande dificuldade, principalmente em função da necessidade de apresentar exemplos de acordo com o conteúdo ministrado. Meliá (1999) lembra que muitos povos indígenas usam os processos pedagógicos escolares próprios como estratégia para sustentar sua alteridade, uma educação indígena que permite que o modo de ser e a cultura venham a se reproduzir nas novas gerações, mas também que essas sociedades encarem com relativo sucesso situações novas, daí a necessidade de ter na aldeia professores com outros saberes, que, neste caso, funcionam como complementares a cultura e saberes do povo indígena.

Os processos pedagógicos que se desenvolvem na escola indígena precisam diferenciar-se. O professor precisa conhecer a cultura, as tradições e a forma de viver da comunidade a que a educação se destina, Arguello (2002) salienta que o etnoconhecimento é peça fundamental na construção de uma escola indígena integrada a comunidade e que seja algo mais que uma escola de brancos pensada para índios, incorporando ao saber dos 
anciãos, as características da educação indígena ancestral e que resgate da escola do branco os saberes necessários a seu fortalecimento e à prática da educação libertadora.

A escola do branco prestigia o pensamento cartesiano, o reducionismo mecanicista, a disciplinaridade, traz implícita a ideia ou princípios do progresso, a escrita, o cálculo, a teoria, o acúmulo, o consumismo, a competição e, apesar de propiciar a utilização dos meios globais de informação, ignora o seu entorno imediato, ignora - conteúdo cultural dos seus alunos e familiares e tende a uma padronização estéril (ARGUELLO, 2002, p. 146).

Em uma escola com essas características, o aluno indígena terá dificuldade de "progresso", mesmo que se esforce, os relatos abaixo são significativos:

"A aprendizagem dos alunos e até mesmo a dos professores não indígenas tem sido muito lento, pois tivemos que aprender um pouco da sua linguagem materna, mesmo porque não trabalhamos somente com a etnia Wai-Wai e sim com várias" (participante 3).

"São participativos e esforçados esses do $5^{\circ}$ ano, mas nem todos acompanham, alguns conseguem entender e se sobressaem, minha turma tem 28 alunos, em que 18 conseguem entender o português e fazerem as atividades, os demais não" (participante 1).

"Recebi um aluno agora do $5^{\circ}$ ano, não conseguia nem escrever 0 alfabeto correto, não sabia escrever as letras corretas, escrevia que eu não entendia nada, eu me desesperei quando recebi cinco alunos com essa dificuldade toda, que não sabia escrever seu próprio nome, eu cheguei com a diretora e a coordenadora pedagógica e disse olha eu não sei o que podemos fazer, tenho até medo e não sei se vamos conseguir chegar ao final do ano com essa turma, posso até correr dela com medo, aí porque estou com medo de chegar ao final do ano e não nenhum aprendizado para essas crianças, porque a responsabilidade da turma é do professor então" (participante 1).

A aula do professor Karaywa advém de uma formação pensada fora da comunidade, assim, as dificuldades se multiplicam e a experiência vai ganhando contornos de "dar um jeito", fazer com que os alunos aprendam o mínimo. A formação de professores para trabalhar nas escolas indígenas 
deveria apontar nesta direção a medida que não existe uma educação indígena genérica, cada povo tem seus signos, sua cultura. A educação que se pretende intercultural precisa respeitar o espaço em que está sendo desenvolvido e a formação continuada do professor deve ter em conta as especificidades de cada povo, saindo da generalidade e se banhando no rio da cultura e sabedoria de cada povo, em processo continuo de aprendizagem.

\begin{abstract}
"Aprendi a falar um pouco Wai-Wai, através da convivência com os demais, alunos principalmente quando fui lotado para ministrar $\circ 5^{\circ}$ ano, foi nesta classe que comecei a me dedicar cada vez mais a língua indígena" (participante 3).
\end{abstract}

$\mathrm{Na}$ EIB os processos de ensino não podem estar desgarrados dos objetivos da escola e estes dos objetivos da comunidade, como nos lembra Freitas (2006) conteúdo e forma estão aprisionados pelos objetivos da escola e o trabalho pedagógico está na dependência de seus objetivos, assim, conteúdo/forma não dependem de objetivos instrucionais determinados pela disciplina ou professor, eles interagem com a função que a sociedade especifica para a escola.

No projeto societário wai-wai, a escola tem duplo objetivo, deve reforçar o laço entre o aluno e a cultura do povo, daí a opção pelo ensino na língua materna nas séries iniciais; e prepara-lo para dar prosseguimento aos estudos, daí a opção em aceitar o ensino das disciplinas da ciência clássica pelos professores não indígenas.

Para os participantes, os processos de ensino têm se mostrado ineficazes para dar conta dessa dupla função, pois as estratégias de transmissão dos conteúdos não têm propiciado os resultados esperados pelos professores, que apontam as diferenças na língua e cultura como principal causa deste insucesso. 


\subsection{Interculturalidade e convivência na aldeia}

Um dos grandes desafios da ElB é conviver com diferentes culturas, diferentes formas de ser e viver, em dialogo respeitoso e que permita a manutenção da identidade indígena, aqui entendida na percepção de sujeito sociológico defendida por Hall (2006), que preenche o espaço entre o interior e o exterior, entre o mundo pessoal e o mundo público, em que o índio projeta a si próprio na identidade cultural do grupo ao mesmo tempo que internaliza seus significados e valores, tornando a identidade do grupo parte dele, o que contribui para alinhar os sentimentos subjetivos com o lugar objetivo que o índio ocupa na aldeia.

\footnotetext{
"Foi um trabalho mais de conhecimento pra mim, para eu conhecer aquela realidade do que ensinar ou outra coisa parecida, praticamente nós fomos trabalhando em conjunto, aprendendo juntos, porque eu aprendia um pouco da cultura deles e eles da minha" (participante 1).
}

Educação intercultural é, portanto, a convivência no espaço escolar10 de saberes de diversas matizes, que se relacionam, se complementam, se aprendem uns com os outros, sem relação de hierarquia entre eles, diferenciando-se, portanto, do histórico da educação indígena sempre marcada pela tentativa de dominação e domesticação do índio.

A ambição do não índio de dominar a cultura do índio nos parece tarefa inócua, não só porque a cultura do índio é diferente da nossa, mais porque cada povo tem sua própria cultura, maneiras próprias de ser e viver, daí não ser possível conceber uma cultura indígena única, universal. Geertz (2008) afirma que a principal razão pela qual os antropólogos fogem das particularidades culturais quando a questão é definir o homem, procurando o refúgio em universais sem sangue é que quando confrontados com a diversidade do comportamento humano, são perseguidos pelo medo do

\footnotetext{
10 Na educação escolar indígena o espaço escolar é a própria aldeia.
} 
historicismo, de se perderem num torvelinho de relativismo cultural tão convulsivo que poderá privá-los de qualquer apoio fixo.

"Primeiro contato com os indígenas foi um impacto inexplicável, pois pra mim foi algo muito prazeroso a vontade de conhecer outra cultura totalmente diferente da minha, em várias questões" (participante 2).

A chegada de um karaywa na aldeia Mapuera é certamente marcada por conflitos de diversas ordens, que se expressam nas vivencias e no estranhamento com a diferença. Os participantes da pesquisa, apesar de não morarem em grandes centros urbanos e dos esforços que fazem para adentrar na cultura wai-wai, carregam consigo sua experiência de formação na escola do não índio, na universidade, bem como formas de ser e viver próprias. O índio wai-wai, por seu turno, tem o apelo da tradição, dos costumes, das lendas e formas de agir próprios do seu povo, assim, se colocam em um mesmo campo formas de saber e viver diferentes, que entram em conflito, mesmo que mascarado na aparência do diálogo.

\footnotetext{
"Foi uma experiência boa principalmente para mim, por ser esta em outra cultura e costumes diferentes" (participante 3).

"Nossas relações são boas dentro da aldeia Mapuera... amizade, companheirismo, respeito e participação da comunidade em nossas atividades" (participante 1).
}

Este apego a tradição funde-se ao próprio viver na comunidade, como nos ensina Geertz (2008), o homem é um animal amarrado a teias de significados que ele mesmo teceu e a cultura são essas teias e a sua análise, não como uma ciência experimental em busca de leis, mas como uma ciência interpretativa, à procura do significado.

\footnotetext{
"Não convivemos diretamente com eles (indígenas) no dia a dia, devido essa falta de contato é que não falamos a língua wai-wai bem, algumas palavras que usamos no dia a dia, que já aprendemos com os indígenas e por ser grande a aldeia e ter outros karaywa para se comunicar" (participante 2).
} 
"A nossa experiência com professores indígenas é muito boa, pois cada um deles também sofreram em aprender a pronunciar a língua portuguesa, e alguns ainda tem essa dificuldade, mas sempre ajudamos, principalmente quando os mesmos estão estudando na universidade" (participante 3).

Observa-se entre os participantes profundo respeito pela cultura WaiWai, o que mostra que as dificuldades encontradas para ensinar derivam das diferenças culturais e de concepções de educação. Grupioni (2008) afirma que, muitos discursos indígenas são construídos a partir de concepções que essencializam traços escolhidos como marcadores substantivos de seus pertencimentos culturais. O índio deste início de século, ao contrário de momentos anteriores em que alguns grupos indígenas até mesmo chegaram a optar pela auto extinção, se orgulha de ser índio, de ser cidadão. Luciano (2006) afirma que este reconhecimento da cidadania indígena brasileira e, consequentemente, a valorização das culturas indígenas possibilitaram uma nova consciência étnica dos povos indígenas do Brasil. Ser índio transformou-se em sinônimo de orgulho identitário. Ser índio passou de uma generalidade social para uma expressão sociocultural importante do país. Ser índio não está mais associado a um estágio de vida, mas à qualidade, à riqueza e à espiritualidade de vida. Ser tratado como sujeito de direito na sociedade é um marco na história indígena brasileira, propulsor de muitas conquistas políticas, culturais, econômicas e sociais.

\section{CONSIDERAÇÕES FINAIS}

Neste artigo relatamos e discutimos a experiência de professores nãoindígenas no fazer pedagógico da Escola Indígena Mapuera, no contexto de desenvolvimento da educação intercultural bilíngue com o povo indígena Wai-Wai, utilizando como instrumento de constituição dos dados entrevista semiestruturada.

Os dados mostraram as muitas dificuldades que os professores não indígenas enfrentam no desenvolvimento do ensino, apontando como principal causa para estas o bilinguismo adotado na organização 
pedagógica da escola, na qual o ensino nos cinco primeiros anos do ensino fundamental é ministrado em língua Wai-Wai e do sexto ao nono ano em língua portuguesa, gerando uma situação que obriga o professor a alfabetizar o aluno na língua portuguesa no sexto ano, no qual já deveria estar ensinando os conteúdos das disciplinas da base nacional comum.

A análise dos discursos dos participantes nos leva a associar as dificuldades apontadas as diferenças culturais e a falta de formação dos professores para trabalhar em situação especifica da escola indígena Mapuera, que tem características diferenciadas. Revela ainda uma concepção de linguagem baseada na leitura da palavra, em contraponto com a língua falada pela comunidade, resultante de processo cultural e identitária das tradições e formas de ser e viver do povo da aldeia Mapuera.

Outro aspecto importante é que as dificuldades para ensinar se relacionam, além das questões culturais e barreiras linguísticas, aos processos de convivência na aldeia $e$ as condições de trabalho docente, se reconhecendo, no entanto, o desejo e esforço dos professores karaywa em aprender pelo menos o básico da língua wai-wai e conhecer a cultura da aldeia para ajudar na educação de seus jovens.

A escolha da entrevista para a produção de dados e da técnica de análise de conteúdo para análise se mostraram adequadas ao desenvolvimento da pesquisa. A compressão do conteúdo das falas em categorias de análise, apesar destas terem se mostrados amplas, cobriram os objetivos propostos para o estudo.

A pesquisa demonstrou o longo caminho a ser percorrido até a efetivação de uma educação indígena verdadeiramente intercultural, que se desenvolva no dialogo respeitoso entre os saberes, que faça da escola um instrumento de afirmação da identidade da comunidade e pugne por um mundo de respeito a diferença e solidariedade entre os povos.

A formação de professores indígenas em cursos superiores para atuar na escola indígena tem sido apontada em estudos, conferencias sobre educação indígena, nos marcos legais e pelo movimento indígena como o caminho para resolver a problemática discutida neste estudo, vez que 
produziria uma educação escolar umbilicalmente ligada ao projeto societário de cada povo.

A EIB já é realidade em muitas aldeias, as correções de rota são necessárias e inevitáveis, a Escola Indígena Mapuera faz parte de um processo de redescobrimento do índio, de afirmação da identidade, do orgulho de pertencimento a um povo com cultura própria e disposto a resistir as tentativas de dominação e doutrinamento. Cabe aos professores karaywa assimilarem a proposta da escola, pesquisar a cultura, desenvolver processos de ensino diferenciado e, acima de tudo, conceber a educação escolar indígena como um processo dialógico, em que os saberes da ciência da tradição se entrecruzam com os saberes da ciência da sociedade nacional, só assim o índio wai-wai terá uma educação de qualidade.

\section{REFERÊNCIAS}

ALVARES, M. M. A Educação Indígena na Escola e a Domesticação Indígena da Escola. Belém/PA. Boletim Museu Paraense Emílio Goeldi. Série Antropologia, No 15, Volume 2, 1999.

ARGUELLO, C. A. Etnoconhecimento na Escola Indígena. In MARFAN, Marilda Almeida (org.). Congresso Brasileiro de Qualidade na Educação: formação de professores: educação indígena. Brasília: MEC, SEF, 2002.

BARDIN, L. Análise de Conteúdo. Lisboa: Edições 70, 2002.

BERGAMASCHI, M. A. Nhembo'e: enquanto o encanto permanece! Processos e práticas de escolarização nas aldeias Guarani. Tese de Doutorado. Universidade Federal do Rio Grande do Sul. Faculdade de Educação. Programa de Pós-Graduação em Educação. Porto Alegre, 2005.

BOURDIEU, P. O poder simbólico. Tradução de Fernando Tomaz. Rio de Janeiro: Bertrand Brasil, 1989.

Brasil. Câmara dos Deputados. Lei de diretrizes e bases da educação nacional: Lei $n^{\circ}$ 9.394, de 20 de dezembro de 1996, que estabelece as diretrizes e bases da educação nacional. 11. ed. - Brasília: Câmara dos Deputados, Edições Câmara, 2015. - (Série legislação; n. 159).

BRASIL, Congresso Nacional. Constituição da República Federativa do Brasil. In Vade Mecun Saraiva. 20 edição. São Paulo: Saraiva, 2015.

BRASIL, Ministério da Educação. Referencial curricular nacional para as escolas indígenas. Brasília: MEC/SEF, 1998. 
BRASIL, Ministério da Educação. Resolução $n^{\circ}$ 5, de 22 de junho de 2012: Define Diretrizes Curriculares Nacionais para a Educação Escolar Indígena na Educação Básica. Brasília: MEC/CNE/CEB, 2012.

CANCLINI, N. G. Culturas Híbridas: estratégias para entrar e sair da modernidade. Tradução Ana Regina Lessa e Heloísa Pezza Cintrão. 4a Edição. São Paulo: Edusp, 2015.

COHN, C. "Escolas Indígenas do Maranhão: um estudo sobre a experiência dos professores indígenas". In SILVA, A. L. da.; FERREIRA, M. K. L. (orgs). Práticas Pedagógicas na Escola Indígena. São Paulo: Global, 2001 - Série Antropologia e Educação.

DESLANDES, S. F. "O projeto de pesquisa como exercício científico e Artesanato intelectual". In DESLANDES, S. F. GOMES, R.; MINAYO, M. C. de S. (orgs). Pesquisa social: teoria, método e criatividade. 26. ed. Petrópolis, RJ: Vozes, 2007.

ERICKSON, F. Qualitative Methods of Research on Teaching. In: WITTROCK, M. (editor), Handbook of Research on Teaching. Third edition. New York: Macmillan Publisching Company, 1986.

FREIRE, J. R. B. A demarcação das línguas indígenas no Brasil. In CUNHA, M. C. da.; CESARINO, P. de N. (orgs). Políticas Culturais e Povos Indígenas. $1^{a}$ edição, São Paulo: Cultura Acadêmica, 2014.

FREITAS, L. C. de. Crítica da Organização do Trabalho Pedagógico e da Didática. $8^{a}$ edição. São Paulo: Papirus, 2006.

GEERTZ, C. A interpretação das culturas. Rio de Janeiro: LTC, 2008.

GRUPIONI, L. D. B. Olhar Longe Porque o Futuro é Longe: Cultura, escola e professores indígenas no Brasil. Tese de Doutorado. Universidade de São Paulo. Faculdade de Filosofia, Letras e Ciências Humanas. Programa de PósGraduação em Antropologia Social. São Paulo, 2008.

HALL, S. A identidade cultural na pós-modernidade. Tradução de Tomáz Tadeu da Silva e Guaraeira Lopes Louro. $11^{a}$ edição. Rio de Janeiro: DP\&A, 2006.

LUCIANO, G. dos S. O Índio Brasileiro: o que você precisa saber sobre os povos indígenas no Brasil de hoje. Brasília: Ministério da Educação, Secretaria de Educação Continuada, Alfabetização e Diversidade; LACED/Museu Nacional, 2006.

MELIÁ, B. Educação Indígena e Alfabetização. São Paulo: Edições Loyola, 1979.

MELIÁ, B. "Educação indígena na escola". Cadernos Cedes, ano XIX, n 49, Dezembro/1999.

MINAYO, M. C. de S. O desafio da pesquisa social. In DESLANDES, S. F.; GOMES, R.; MINAYO, M. C. de S. (orgs). Pesquisa social: teoria, método e criatividade. 26. ed. Petrópolis, RJ: Vozes, 2007. 
PÊCHEUX, M. Análise Automática do Discurso. In GADET, F.; HAK, T. (orgs.) Por uma análise automática do discurso: uma introdução a obra de Michel Pêcheux. Tradução de Bethania S. Mariani et al. $5^{a}$ edição. Campinas, SP: Editora da Unicamp, 2014.

PERRELLI, M. A. de S. Tornando-me professora de ciências com alunos indígenas Kaiowa e Guarani. 2007. 306 f. Tese (Doutorado em Educação Para a Ciência) Faculdade de Ciências, Universidade Estadual Paulista Júlio de Mesquita Filho. Bauru: 2007.

SECCHI, D. Apontamentos acerca da regularização das escolas indígenas. In Congresso Brasileiro de Qualidade na Educação: formação de professores: formação de professores: educação indígena. Marilda Almeida Marfan (org.). Brasília: MEC, SEF, 2002.

SOUSA, J. V. de. A identidade do sujeito social, ético e político e o projeto pedagógico da escola. In VEIGA, I. P. A.; FONSECA, M. (orgs.) As dimensões do projeto político pedagógico. $8^{a}$ edição. São Paulo: Papirus, 2010.

TRIVINÕS, A. N. S. Introdução à Pesquisa em Ciências Sociais: a pesquisa qualitativa em educação. 20ª Reimpressão. São Paulo: Atlas, 2011.

VILLARES, L. F. Estado Pluralista?: o reconhecimento da organização social e jurídica dos povos indígenas no Brasil. 2013. 460 f. Tese (Doutorado em Direito). Faculdade de Direito. Universidade do Estado de São Paulo. São Paulo: 2013.

Recebido em: Agosto de 2017 Aprovado em: Fevereiro de 2018 